\title{
Health Service Quality Management at dr. Siswanto Air Force Hospital, Colomadu, Karanganyar, Central Java
}

\author{
Dwi Marwanto'), Bhisma Murti'), Didik Gunawan Tamtomo') \\ 1)Masters Program in Public Health, Universitas Sebelas Maret \\ 2)Faculty of Medicine, Universitas Sebelas Maret
}

\section{ABSTRACT}

Background: Patient satisfaction is an important indicator of health care success. Patients assess the quality of service received based on their satisfaction with the services provided. The purpose of this study was to describe the quality management of health services at dr. Siswanto Air Force Hospital (RSAU) Colomadu, Karanganyar.

Subject and Method: This study is a qualitative study with a descriptive approach. The study was conducted from March to May 2021. The data for this study were taken from two sources, namely internal hospitals as health service providers and the community as users of health services. Informants in this study were the director of the dr. Siswanto Air Force Hospital, staff of dr. Siswanto Air Force Hospital, and 7 patients who used health services at dr. Siswanto Air Force Hospital. Data was collected by means of in-depth interviews, observations, documents and focused group discussions. The data analysis techniques carried out were data reduction, data display and conclusion and also verification.

Results: The quality of health services from the side of health service users (patients) showed that dr. Siswanto Air Force Hospital has good quality health services based on the following aspects: (1) reliability: patient regis- tration services, administrative management, provision of treatment rooms that are fast and easily accessible to patients, (2) assurance: health personnel have a polite, friendly, and respectful attitude towards patients, (3) tangible: the hospital room is comfortable, the staff is neat and clean, and medical equipment is complete, clean, and ready to use, (4) empathy: the officer gives special attention to patients and patient complaints, and there is no difference in attitude and treatment in general patient care and insurance, and (5) responsiveness: there is good communication from hospital staff to patients and quick action if the patient needs immediate help.

Conclusion: The quality of health service management at dr. Siswanto air force hospital fulfills the criteriaof reliability, assurance, tangible, empathy and responsiveness.

Keywords: Management of health services, quality of health services

\section{Correspondence:}

Dwi Marwanto. Masters Program in Public Health, Universitas Sebelas Maret. Jl. Ir. Sutami 36A, Surakarta 57126, Central Java. Email: dwiantox74@gmail.com. Mobile: o82138064130.

\section{Cite this as:}

Marwanto D, Murti B, Tamtomo DG (2021). Health Service Quality Management at dr. Siswanto Air Force Hospital, Colomadu, Karanganyar, Central Java. J Health Policy Manage. 06(03): 182-189. https://doi.org/10.26911/thejhpm.2021.06.03.03.

(c) (i) (-) Journal of Health Policy and Management is licensed under a Creative Commons Attribution-NonCommercial-ShareAlike 4.0 International License.

\section{BACKGROUND}

Patient satisfaction is commonly used as an indicator for measuring the quality of health services. Patient satisfaction is related to timeliness, efficiency, and health services centered on patient needs 
(Prakash, 2010). Positive feedback from health service users can increase the good judgment of health care providers, which indirectly expands the promotion of their agency, while negative feedback can reduce patients' interest in using their health services (2016).

As recipients of health services, patients are an important source of information about whether they are receiving proper health care. The patient's experience during treatment can trigger the emergence of information about the need for the types of changes needed to close the gap between the care provided by the hospital and what patients should receive. Patients can receive quality health services in terms of accessibility and affordability of health care, promptness of early diagnosis and treatment, thereby ensuring an early return to productivity and being treated with empathy and respect (Cleary, 2003).

The parameters of the quality of health services in terms of health care providers are the provision of care in accordance with established practices, the availability of resources, and the provision of workers with high knowledge, skills, and competencies (Gregory et al., 2005).

Health care providers are responsible to the community for the costs they incur to obtain optimal health care. They therefore view quality in terms of ensuring patient safety and preventing inappropriate treatment. At the same time, health care providers strive to meet the requirements of both recipients and care providers at an acceptable cost (Kapoor, 2011).

The quality of health services is also related to structure, process and outcomes. Structures represent facilities and human resources while processes represent the various clinical, supportive and administrative interactions between providers and recipients. Results reflect changes in health status i.e. relief of symptoms or cure of disease. Reductions in morbidity and/or mortality, prevention of illness or accidents and employee and patient satisfaction are also outcomes. The focus of all quality efforts should be on the results produced (Kapoor, 2011).

The purpose of this study was to describe the quality management of health services at dr. Siswanto air force hospital, Colomadu, Karanganyar, Central Java.

\section{SUBJECTS AND METHOD}

\section{Study Design}

This is a qualitative study with a descriptive approach. The study was conducted from March to May 2021.

\section{Data Source}

The data in this study were taken from two sources, namely the internal hospital as a provider of health services and the community as users of health services.

\section{Study Informants}

Informants in this study were the director of the dr. Siswanto Air Force Hospital, staff of dr. Siswanto Air Force Hospital, and 7 patients who use health services at $\mathrm{dr}$. Siswanto Air Force Hospital.

\section{Study Instruments}

Data collection was carried out by in-depth interviews, observations, documents and focused group discussions.

\section{DataAnalysis}

The data analysis techniques carried out were data reduction, data display, conclusions and verification.

\section{Data Validity}

Assessment of the data confidence is done by triangulation. Triangulation is a combination of various methods to examine interrelated phenomena from different perspectives. The study triangulation used are as follow:
a. Method triangulation
b. Inter-researcher triangulation 
c. Data source triangulation

d. Theory Triangulation

\section{RESULTS}

\section{Quality of health services from the side of health service users (patients)}

The quality of health services from the side of health service users (patients) showed that dr. Siswanto Air Force Hospital has good quality of health services based on the following aspects: (1) reliability: patient registration services, administrative management, provision of treatment rooms that are fast and easily accessible to patients, (2) assurance: health personnels have a polite, friendly, and respectful attitude towards patients, (3) tangible: the hospital room is comfortable, the staff is neat and clean, and medical equipment is complete, clean, and ready to use, (4) empathy: the officer gives special attention to patients and patient complaints, and there is no difference in attitude and treatment in general patient care and insurance, and (5) responsiveness: there is good communication from hospital staff to patients and quick action if the patient needs immediate help.

\section{2. Quality of health services from the side of health service providers (hospitals)}

The quality of service from the aspect of health service providers is influenced by organizational leadership and strategy, culture and teamwork (culture and teamwork), customer focus, provision of facilities and infrastructure, and competence of health workers.

According to the informant (Director of dr. Siswanto Air Force Hospital) stated that the basic strategy of a health service organization is the availability of quality human resources, the availability of inspection infrastructure facilities, and an easy service system. One of the strategies carried out by the hospital during the Covid-19 pandemic is to open an online patient registration service. Patients do not need to come directly to the hospital to register. This is done to avoid long queues or crowds. Patients are encouraged to come according to the hospital service hours that have been determined during online registration.

Management of dr. Siswanto hospital has implemented the organizational culture including values and principles that influence health services by instilling the vision, mission and goals of the hospital carried out by all officers.

The results of observations by researchers show that there is good cooperation between health workers and nonmedical officers at dr. Siswanto Air Force Hospital.

\section{DISCUSSION}

1. Quality of health services from the side of health service users (patients)

Quality of service has become a key issue for management in the service sector. This has been the result of increased customer demand for higher quality services and, consequently, the pressure for services to satisfy customers' demands. Health service quality is important to ascertain an optimal level of patient satisfaction(Papanikolaou and Zygiaris, 2014).

Concerns for healthcare quality and patient safety have increased, especially in the context of cost, malpractice, and healthcare reform (Lee and Kim, 2017).

Several studies categorized measurement items of healthcare service quality as empathy, responsiveness, reliability assurance and improvement of care services (Carmen, 1990; Parasuraman et al., 1988; Doran and Smith, 2004; Scobie et al., 2006). 
The SERVQUAL instrument was designed to measure service quality using both the gap concept and service quality dimensions. The original SERVQUAL contains 22 pairs of the statements using a seven - point Likert scale, on five service quality dimensions which are: (1) tangibles, (2) reliability, (3) responsiveness, (4) assurance, and (5) empathy. According to this scale, quality defines a gap between perceived expectation and performance and if the performance exceeds expectations the customer will attain more satisfaction (Kopalle and Lehmann, 2001; Kalajaa et al., 2016).

\section{a. Tangibles}

Tangibility is the physical evidence of the service, for instance, the appearance of the tools, equipment, and physical facilities used to provide the service (Nutiet al., 2009; Lobo et al., 2014; Murante et al., 2014).

A study by Umoke et al. (2020) found that tangibility dimension focuses on infrastructural facilities like labs, equipment, hygienic conditions of toilets, healthy hospital environments, health conditions, proper seating facilities for visitors, cleanliness of toilets, cleanliness of the patient room, facilities of hospital's research, pharmacy facilities, etc.

Another studies also similarly stated that tangibility has a significant correlation with patient satisfaction (Iloh et al., 2012; Odetola, 2015; Ibraheem et al., 2013; Rehaman and Husnain, 2018).

\section{b. Assurance}

Assurance is about knowledge, skills, and expertise of the health personnels involved in delivering services and the ability to create trust and confidence among their patients. The result revealed that most patients were satisfied with the thoroughness of the medical examination, instruction on medication/follow-up care, medical advice receivedand competence of health personnels (Umoke et al., 2020).

The results of this study indicate that the health care providers at this hospital are friendly, polite, and respectful of patients. They also have the necessary knowledge and skills when dealing with patients. The results of this study are in line with Assefa et al., 2011; Adekanye et al., 2013, Ndambuki, 2013; Fatima et al., 2018.

\section{c. Reliability}

Reliability is the ability of health services to provide quality health services. The results of this study indicate that patient registration services and administrative arrangements are easy and fast, can be done with an online system, and do not cause long queues of health service visitors.

This study is in accordance with Aldana et al. (2001), Ogunfowokan and Mora (2012), Amole et al. (2015), Odetola (2015), Zarei et al. (2015), who reported that reduction in waiting time and consulting time improves patients' satisfaction

Respondents were dissatisfied with clinician's ability to prescribe good medicine. This observation substantiates respondent's dissatisfaction on proper prescription of medication mentioned in reliability dimension (Khamis and Njau, 2014).

\section{d. Responsiveness}

Responsiveness is the level of willingness to help patients and provide prompt service by hospital staff. The results of this study indicate that according to informants (patients at dr. Siswanto Hospital), they will immediately respond to patient complaints properly by health workers.

The results of Umoke et al. (2020) shows that the responsiveness dimension increases patient satisfaction, which includes clarity of information provided by health workers, explanation of examination and diagnosis results, treatment received, 
and the willingness of health workers to listen to complaints from patients.

Respondents were most dissatisfied with the health care staff's respect for patients. Patients' perceptions of health care provider behavior, such as respect, influence their views on quality of care (Leonard, 2008, Muhondwa et al., 2008; Khamis and Njau, 2014).

\section{e. Empathy}

The empathy dimension is reflected in the attitude of health service providers in providing protection and approaches, as well as trying to meet the needs and know the desires of consumers. Empathy is personal attention and understanding the patient's needs. The results of this study indicate that health workers do not provide different treatment between patients with independent costs and patients with insurance.

A study of patient satisfaction in hospitals shows the importance of care provided by doctors and nurses. They also emphasized the importance of the availability of services, including those provided by doctors and nurses, and communication between medical staff and patients, patients' trust in doctors, and availability of nurses both day and night. This study is also supported by Vahey et al. (2004), Iliyasu et al. (2010), Ross and Venkatesti (2015), which state that the attitude of health workers is positively related to patient satisfaction (Adamus and Adamus, 2012).

\section{Quality of health services from the side of health service providers (hospitals)}

Quality is a complex and multifaceted concept that requires the simultaneous design and implementation of a combination of discrete interventions. Quality of health care from the health care provider's perspective involves the right care, at the right time, responding to the needs and preferences of service users, while minimizing harm and wasting resources. Quality health care increases the likelihood of desired health outcomes and is consistent with seven measurable characteristics: effectiveness, safety, people-centredness, timeliness, equity, integration of care and efficiency World Health Organization (2018).

According to Mosadeghrad (2014), the factors that affect the quality of health services in terms of health service providers include human resource competence (knowledge and skills), motivation, health care system, resources and facilities, leadership and management of health services, and the development of cooperation and collaboration.

\section{AUTHOR CONTRIBUTION}

Dwi Marwanto collected data, conducted interviews, did observations, lead focus group discussions, did daya analysis, and wrote the articles. Bhisma Murti and Didik Gunawan Tamtomo triangulated and reviewed the research data.

\section{FUNDING AND SPONSORSHIP}

No external financing.

\section{CONFLICT OF INTEREST}

The authors state that they have agreed to the results of this study for publication and that there is no conflict of interest.

\section{ACKNOWLEDGMENT}

The author thanks to dr. Siswanto air force hospital, Colomadu, Karanganyar, that has given permission to conduct research, and to research informants who have helped as resource persons for collecting research data information. 
Marwanto et al./ Health Service Quality Management at dr. Siswanto Air Force Hospital

\section{REFERENCE}

Adekanye, AO, Adefemi SA, Okuku AG, Onawola KA, Adeleke IT, James JA (2013). Patients' satisfaction with the healthcare services at a north central Nigerian tertiary hospital. Niger $\mathrm{J}$ Med. 22(3): 218-224. PMID: 24180151.

Aldana JM, Piechulek H, al-Sabir A (2001). Client satisfaction and quality of health care in rural Bangladesh. Bull World Health Organ. 79(6): 512-517. https://www.ncbi.nlm.nih.gov/pubm ed/11436472.

Assefa F, Mosse A, Hailemichael Y (2011). Assessment of clients' satisfaction with health service deliveries at Jimma University specialized hospital. Ethiop J Health Sci. 21(2): 101109. https://dx.doi.org/10.4314\%2Fejhs.v21i2.69050.

Cleary DP (2003). A hospitalization from hell: a patient's perspective on quality. Ann Int Med. 138(1): 33-39. https://doi.org/10.7326/ooo3-4819-138-1200301070-00009.

Clemes MD, Ozanne LK, Laurensen WL (2001). Patients' perceptions of service quality dimensions: an empirical examination of health care in New Zealand. Health Mark Q. 19(1): 3-22. https://doi.org/10.1300/jo26v19no1_ 02.

Doran D, Smith P (2004). Measuring service quality provision within an eating disorders context. Int $\mathrm{J}$ Health Care Qual Assur. 17(7): 377-388. https://doi.org/10.1108/095268604105631 86.

Vahey DC, Aiken LH, Sloane DM, Clarke SP, Vargas D (2004). Nurse burnout and patient satisfaction. Med Care. 42(2): 1157-1166. https://doi.org/10.1097/o1.mlr.0000109126.50398.5a.
Fatima T, Malik SA, Shabbir A (2018). Hospital healthcare service quality, patient satisfaction and loyalty: An investtigation in context of private healthcare systems. Int J Quality Reliability Manage. 35(6) 1195-1214. https://doi.org/10.1108/IJQRM-02-2017-0031.

Gregory D, Way C, Barrett B, Parfrey P (2005). Healthcare quality from the perspective of healthcare providers. $\mathrm{J}$ Health Ser Res Policy. 10(2): 48-57. https://doi.org/10.1258/13558190577 4424456.

Gupta KS, Rokade V (2016). Importance of quality in health care sector: A review. J Health Manage. 18(1): 84-94. https://doi.org/10.1177\%2Fo972063415625 527.

Ibraheem WA, Ibraheem AB, Bekibele CO (2013). Socio-demographic predictors of patients' satisfaction. Afr J Health Sci. 12: 87-90. https://dx.doi.org/10.4103/2384-5589.134902.

Iloh GU, Ofoedu JN, Njoku PU, Odu FU, Ifedigbo CV, Iwuamanam KD (2012). Evaluation of patients' satisfaction with quality of care provided at the National Health Insurance Scheme clinic of a tertiary hospital in SouthEastern Nigeria. Niger J Clin Pract. 15(4): 469-474. https://doi.org/10.4103/1119-3077.104529.

Iliyasu Z, Abubakar IS, Abubakar S, Lawan UM, Gajida AU (2010). Patients' satisfaction with services obtained from Aminu Kano Teaching Hospital, Northern Nigeria. Niger J Clin Pract. 13(4): 371-378. https://www.njcponline.com/temp/NigerJClinPract13437 1-5017797_135617.pdf.

Kapoor P (2011). Why quality in healthcare. Med J Armed Forces India. 67(3): 206-208. https://dx.doi.org/10.1016\%2FSo377-1237(11)60040-3. 
Marwanto et al./ Health Service Quality Management at dr. Siswanto Air Force Hospital

Khamis K, Njau B (2014). Patients' level of satisfaction on quality of health care at Mwananyamala hospital in Dar es Salaam, Tanzania. BMC Health Serv Res. 14: 400. https://doi.org/10.1186/1472-6963-14-400.

Lee DH, Kim KK (2017). Assessing healthcare service quality: a comparative study of patient treatment types. Int $\mathrm{J}$ Qual Innov. 3(1). https://doi.org/10.1186/s40887-016-0010-5.

Leonard KL (2008). Is patient satisfaction sensitive to the changes in the quality of care? An exploitation of the Hawthorne effect. J Health Econ. 27(2): 444-459. https://doi.org/10.1016/j.jhealeco.2007.07.004.

Lobo A, Duarte P, Carvalho A, Rodrigues V, Monteiro MJ, Alves H (2014). The association of equity, accessibility, and price with primary healthcare user's satisfaction. West J Nurs Res. 36(2): 191-208. https://doi.org/10.1177/0193945913497830.

Mosadeghrad AM (2014). Factors influencing healthcare service quality. Int $\mathrm{J}$ Health Policy Manag. 3(2): 77-89. https://dx.doi.org/10.15171\%2Fijhpm .2014 .65 .

Muhondwa E, Leshabari M, Mwangu M, Mbembeti N, Ezekiel M (2008). Patient satisfaction at Muhimbili National Hospital in Dar Es salaam, Tanzania. East Afr J Public Health. 5(2): 67-73. PMID: 19024413.

Murante AM, Seghieri C, Brown A, Nuti S (2014). How do hospitalization experience and institutional characteristics influence inpatient satisfaction? A multilevel approach. Int $\mathrm{J}$ Health Plann Manage. 29(3): e247-e260. https://doi.org/10.1002/hpm.2201.

Ndambuki J (2013). The level of patients' satisfaction and perception on quality of nursing services in the Renal unit,
Kenyatta National Hospital Nairobi, Kenya. Open J Nurs. 3(2): 186-194. http://dx.doi.org/10.4236/ojn.2013.3 2025.

Nuti S, Bonini A, Murante AM, Vainieri M (2009). Performance assessment in the maternity pathway in Tuscany region. Health Serv Manage Res. 22(3): 115-121. https://doi.org/10.1258/hsmr.2008.008017.

Odetola TD (2015). Health care utilization among rural women of child-bearing age: a Nigerian experience. Pan Afr Med J. 20: 151. https://doi.org/10.11604/pamj.2015.20.151.5845.

Ogunfowokan O, Mora M (2012). Time, expectation and satisfaction: patients' experience at National Hospital Abuja, Nigeria. Afr J Prim Health Care Fam Med. 4(1): 398. https://dx.doi.org/10.4102\%2Fphcfm.v4i1.398.

Papanikolaou V, Zygiaris S (2014). Service quality perceptions in primary health care centres in Greece. Health Expect. 17(2): 197-207. https://dx.doi.org/10.1111\%2Fj.1369-7625.2011.00747.x.

Parasuraman A, Zeithaml V, Berry L (1988) SERVQUAL: a multiple item scale for measuring consumer perceptions of service quality. J Retail 64(1): 12-40. https://psycnet.apa.org/record/198910632-001.

Prakash B (2010). Patient Satisfaction. J Cutan Aesthet Surg. 2010 Sep-Dec; 3(3): 151-155. https://dx.doi.org/10.4103\%2Fo974-2077.74491.

Ross DS, Venkatesti R (2015). An empirical study of the factors influencing quality of healthcare and its effects on patient satisfaction. Int $\mathrm{J}$ Innov Res Sci Eng Technol. 4(2): 54-59. http://www.ijirset.com/upload/2015/februa ry/9_AN_EMPIRICAL.pdf.

Scobie S, Thomson R, Mcneil J, Phillips P (2006). Measurement of the safety 
Marwanto et al./ Health Service Quality Management at dr. Siswanto Air Force Hospital

and quality of healthcare. Med J Aust. 184(10):S51-S55. http://dx.doi.org/10.5694/j.1326-5377.2006.tboo363.x.

Umoke MJ, Umoke PCI, Nwimo IO, Nwalieji CA, Onwe RN, Ifeanyi NE, Olaoluwa AS (2020). Patients' satisfaction with quality of care in general hospitals in Ebonyi State, Nigeria, using SERVQUAL theory. SAGE Open Med. 8: 1-9. https://doi.org/10.1177\%2F2050312120945129.

World Health Organization (2018). Delivering quality health services: a global imperative for universal health coverage. Geneva: World Health Organization for Economic Co-operation and Development, and The World Bank.

Zarei E, Daneshkohan A, Pouragha B, Marzban S, Arab M (2015). An empirical study of the impact of service quality on patient satisfaction in private hospitals, Iran. Glob J Health Sci. 7(1): 1-9. https://doi.org/10.5539/gjhs.v7n1p1. 